\title{
An Overview of Intelligent Moving Machines (IMM)
}

\author{
D.K. Chaturvedi \\ Department of Electrical Engineering \\ DEI, Dayalbagh
}

\author{
Amit Yadav \\ Department of Electrical Engineering \\ DEI, Dayalbagh
}

\begin{abstract}
The intelligent moving machine is design for fast response, cost effective and obstacle avoiding in its path. The introduction of intelligent behavior of moving machine can adapt the change taken place in the environment and or operating conditions etc. This adaptive behavior of moving machine makes it more robust and useful for industrial applications. The paper deals with an overview of Intelligent Moving Machine (IMM) based on two broad category. Firstly, overview based on applications of intelligent moving machine and secondly, technique based intelligent moving machine.
\end{abstract}

\section{Keywords}

Kinect sensor, Motor Drive, Hardware Implementation, Softcomputing approach.

\section{INTRODUCTION}

The Intelligent moving machine which may avoid the obstacle, move intelligently and reach to the destination safely, accurately in minimum time and minimum cost. Earlier many moving machines were developed using different techniques for a real time path finding system. Man-Intelligent moving machine has become an important topic in the robots community. An advanced intelligent moving machine must integrate capabilities to detect human's presence in their vicinity and interpret their motion for an active interaction; the machine must also be able to track the static and dynamic obstacle in its path. The humans and moving machines coexist, closely interact and perform a certain amount of work. This research work is divided into two parts. The first part deals with the development of Safe Intelligent Moving Machine (SIMM), which maintains a certain relative positional relationship between the human and moving machine. The moving machine can carry loads that are required by people working in hospitals, airports, and industries etc. These machines are considered as an intelligent moving machine because they are able to interact with its environment and learn from the surroundings automatically. Interacting with nature and indoor situation involves learning and adaptation from changing environment. The intelligent machine can work as an assistant for humans in various situations. The second part of work related to the intelligent moving machine is obstacle avoidance in real time situation. The real time obstacle avoidance system of intelligent moving machines will be developed with help of soft computing techniques.

\section{MOTIVATION}

How does a person move in unknown areas and unknown paths? Human Intelligence, Intuitiveness, capability of adaptation and the way obstacle avoidance in real time dynamic environment inspired the researcher to develop an intelligent moving machine which is safe, intelligent and optimally find its path in the static and dynamic, real time environment.

\section{HISTORY OF MOVING MACHINES}

Early work leading to today's industrial machines can be traced to the period immediately followed by World War II. During the late 1940's research programs were started at the Oak Ridge and Argonne National Laboratories to develop remote mechanical manipulators. These systems were of the "master-slave" type and designed to reproduce faithfully motions made by a human operator. The master manipulator was guided by the user through a sequence of motions, while the slave manipulator duplicated the master unit as closely as possible. In the mid - 1950's the mechanical coupling was replaced by electric and hydraulic power in manipulators such as General electric's (GE) Handyman [1, 2].

While programmed moving machine offered a novel and powerful manufacturing tool. It became evident in the 1960's that the flexibility of these machines could be enhanced. The researchers at the Stanford University developed computer with hands, eyes and ears, manipulators, T.V. Cameras, and microphones. The system recognizes and manipulates in accordance with instructions [3]. In 1974, Cincinnati Milacron introduced its first computer-controlled industrial moving machine. "The Tomorrow Too", it could lift as well as track moving objects, since then various control methods have been proposed for serving manipulators. In general, it is the fact that "intelligence" is capable for learning and adopts from the environment. When we talk about intelligent machines, the first thing that comes in our mind is robots. In fact, robots have been developed as the substitute of human and perform lot of task in daily indoor environment repetitively. However, robots are operated based on algorithm and fully controlled environment are not consider as an intelligent moving machines. Such robot easily fails when the application contains some unexpected or uncertain situation and if proper safety codes are not followed then it is very risky. Unlikely, intelligent moving machines can perform task and can be more useful when operating in uncertain, unpredictable situations. These intelligent moving machines have learning capability to enhance and sharpen its own existing knowledge for similar situations improve its own performance.

\section{APPLICATION BASED OVERVIEW 4.1 Micro Aerial Vehicle (MAV)}

There are some aerial target and missions that are not suitable for human pilots because of dangerous operations or it takes a long time to complete the task. Yet, these tasks are very important for our defense forces. MAVs have been invented to carry out such mission-tasks. A MAV comprises onboard processing abilities, vision, global positioning navigation and wireless communication. One of the main advantage of MAV is to navigate in an uncertain environment, which is known as undefined or risky environment and/or to perform the require task at the same time [4]. As it is not possible to navigate, the MAV has to 
learn from its outdoor environment, and adapt the changes as they require to complete the task and to reach the destination. The MAV used to collect the information from the atmosphere between satellite communication and ground base station. The MAV is able to observe the portion of planet that never seen before [5]. The MAV is designed with special cameras and multi sensors, and is able to monitor the situations. It has the capabilities of realtime processing the weather information.

\subsection{Underwater Robot}

The underwater invention has attracted the attention of researchers and engineers for ages, as they are many parts of the sea that are unknown to human beings. Another purpose for exploring the oceans is because of interests, communication, oil pipe lines, and gas lines are placed under sea water. This research in intelligent machines gave new dimensions that are capable for inspection of line and they can maintain the fault under water. Today, remotely operated water robots have been used to control and maintain the underwater operations safe An underwater robot is to inspect and capable to repair a fault in pipelines [6]. The robot is controlled from the instructions of fuzzy rule based expert system and it has a quality to complete the task in uncertainty and hazy environment.

\subsection{Space Vehicle}

One of the best applications of moving machines is space robots. In this research one of the opportunity is latest Mars rovers which sent by many space agencies like NASA and ISRO. Its main target is to take pictures of Mars, and send them to Earth [7].

\subsection{Humanoid Moving Machine}

Humanoid machine are designed to work like humans. It contains movement, intelligence and activities like a human. This intelligent machine can sense, actuate, plan, control and can move. Each of these intelligent moving machines has its features. ASIMO is fast moving robot. So this machine can walk and also able to detect the obstacle in its path. This intelligent moving machine is able to control its motions and can do conversation with the humans by its own intelligent like face expressions, movements of lips, and behavior.

\subsection{Other Moving Machines}

Unmanned Combat Air Vehicle (MAV) [8] the main objective of this work is to provide sharp strike on the target by missile and emerging age of intelligent machine in science and technology.Similarly, Micro-mechanical Flying Insect (MFI) is an insect like machine which capable to fly autonomously in the outdoor environment. Medical Micro robot (MMR) is very useful project in medical department and the size of this robot is very micro and it used to transmit images and deliver the payload.

\section{TECHNIQUE BASED OVERVIEW}

\subsection{Neural-Based Approach}

The development of intelligent machines that are able to assist humans or performing independent tasks is one of the popular research areas [9]. In 1981, it has been shown that by implementing a variety of time-saving strategies, detection can be achieved using a sequential support machine, this is an interesting and powerful pattern classification method usable in intelligent machine. Also, a rigorous comparison with other gesture detector approaches in terms of speed and accuracy was conducted [10].
Dynamics motion deals with mathematical modelling and formulation of equations for vehicle motion. Such equations are useful for simulation of dynamic equations of motion in the outdoor environment. The design of control equations for static and dynamic obstacle observation in moving machines are important [11]. Networks of sensors have been used for detecting and avoiding obstacles while machine is moving. The moving machine design is based on the map of its environment to explore objects such as path obstacles and the strategy is made to avoid them. For an autonomous mobile machine the difficulty is compounded in the person detection task because the motion of the target is heavily masked by the background motion generated by the machine movement [8]. This approach uses image moving measurement so that it does not suffer from feature avoiding methods. The system is different from most real time obstacle avoidance systems. Conventional intelligent approaches to reduce the amount of processing and then applied to develop the intelligent moving machines.

\subsection{Distributed Sensor Network Approach}

The distributed sensor network based machines are simple in structure and handle a lot of data [12]. These type of moving machine uses many intelligent sensors to cope up with the situations [2]. It has been reported that the approach of a human and a moving machine leads to interactions. The intelligent moving machines which are always find static and dynamic obstacle while moving in forward and backward directions [13]. In this work an intelligent environment is used in order to solve the problems. A moving machine uses multiple intelligent sensors, which are distributed in the outdoor environment. The distributed sensors recognize the obstacles and the moving machine is controlled from control commands [14]. It is one of the applicants located in one level higher than the mobile machine position estimation module. After a brief review, the aim is to develop a intelligent moving machine provided with simple and robust relative location technologies that do not require structuring the environment. They may have simple semi-reactive strategies that do not require the use of internal maps and the ability to find the smooth path [15]. This approach in based on a control system able to display and integrate an exploration, obstacle avoidance, target following behaviour and a relative location device based on an single emitter and a directional sensor system. The proposed method utilizes the error between the observed and estimated image coordinates to localize the moving machine controls. The Kalman filtering scheme is used to estimate the location of moving machine [16]. The proposed approach is applied for a moving machine in Intelligent (I) space to show the reduction of uncertainty in determining of the location of the machine. Its performance is verified by computer simulation [17]. In this approach the images of an obstacle are used as an absolute position estimation method for a obstacle avoidance machine in the I-space was presented. The Kalman filtering technique was adopted for experimental estimation. Next, the positions of the obstacle and the moving intelligent machine in I-space were measured by DINDs. It was observed that position estimation accuracy depends on the path of the walking human. Intelligent machine have to be able to detect and track the obstacles in a fast and reliable way. Many researchers present a solution for the avoiding obstacle problem that integrates hand and face detection, which are 
obtained respectively from the laser and the camera of a moving machine. The performance of three different techniques i.e. Extended Kalman Filter (EKF), Unscented Kalman Filter (UKF) and sampling Importance re-sampling particle filter [18]. While analyzing accuracy and robustness of moving machine in the hurdle path, obstacle tracking and avoiding system, UKF not only performs better than the EKF, but also require less hardware resources and better computational efficiency.

\subsection{Vision- based Approach}

In the development of industrial moving machine there is a target criterion as the ability to recognize individuals using vision, and to understand the situations in order to provide various real-life services. Real time obstacle avoidance machine developed until now use uses various types of cameras for detecting a target and some of them use other sensors [19]. This newly developed moving machine adopts a stereo vision system, and additionally a Laser Range Finder (LRF) is mounted on the vehicle to enhance the performance or avoidance in motion. The moving machine has to get the information of the target recognize it by some methods and continue following and track the obstacle in its path it quickly start avoiding it. The system uses accurate measurements by operating in combination with LRF. This system has a feature to change the fusion rate of vision and LRF data according to the congestion level of the movement space, and improve its performance [20]. The knowledge of static and dynamic obstacles in path is used in accomplishing a desired path finding technique. In this fusion technique the fusion rate depend on congestion information [21]. An advanced application using sensors independently are subject to an unavoidable limit. So, a system design integrating information from two or more types of sensor is required. Because the vision data containing abundant information plays a key role in the complex system, further development of the vision system is desirable.

\subsection{Silhouette Extraction Approach}

In a study [2] a new integrated computer vision system designed to detect multiple ambiguities and extract their silhouette with a pan-tilt stereo, camera, so that it can assist in avoiding and recognition in the field of Human-moving machine Interaction [22]. The proposed system was evaluated with respect to ground truth table data, and it was shown to detect and tracking the obstacle in its path. People and object can track very well and also produce highquality silhouette [23]. Recently, machine systems for industries, personal services, and professional services have been developed by many researchers. The functions of moving machine sensors are divided into categories internal and external state. Internal state sensor is used for obstacle detection which used to design a machine and external sensors for range variables. In obstacle avoidance distribution the scene are different enough to be separated, for the tracking and obstacle avoidance methods [24]. This will take us from the noise and finally to catch the primitive edge of intensity discontinuity. The low level components are not easily recognized, so that we are focusing on this stage or very minor obstacles in the path. This system is based on multi-sensor based detection and tracking system for real time moving machine. The proposed approach is based on practical and effective solution for real time movement of moving machine in populated environments [25]. A hybrid approach to obstacle tracking was adopted which is based on a new algorithm for path detection and it works well even in challenging situations.

\subsection{Peer-to-Peer Communication Approach}

Avoiding and tracking system is most useful in two respects [26]. First, it allows a target object to be tracked when laserbased face data ceases and the target walks behind a box [27]. Sensing machine are periods during which the tracker are periods during which the tracker updated the persons position using only the vision based estimate, hence the constant radius but changing angle, leading to an arc-like appearance. Secondly, the object tracking system allows a particular thing to track. The vision board initially locate the largest obstacle so that the overall system performs well. As a result it is capable of detecting and avoiding the obstacle in its path and manages it in a correct way. Fast obstacle detection for indoor moving machine, an obstacle detection algorithm was developed to address challenges including occlusions due to cluttered environments, changing backgrounds due to the moving machine motion, and limited on-board computational resources [28]. Obstacle detection in autonomous indoor machines is very important and very challenging task. A depth image based system detection algorithm successfully detects obstacles under challenging conditions such as occlusion, clutter [29].

\subsection{Optical flow and Kalman filter approach}

Tracking and avoiding moving objects is one of the tedious task for motion analysis and understanding of moving machines [30]. The Kalman Filter (KF) has commonly been used for estimation and prediction of the target position in next stage. A number of approaches are used for prediction and detection of these obstacles which are based on the traditional Kalman filter [31]. High level vision processes to attempt various types of obstacles in the path uses optical flow algorithm which makes things easier. In the $\mathrm{KF}$ approach, it is presumed that the behaviour of a moving target could be characterized by a predefined model, and the models can be represented in terms of a state vector [3] The moving machine is designed to track objects by spinning left and right to keep the object in sight and driving forward and backward to maintain a constant distance between the machine and the object. Tracking with moving machine is an active research area and many successful systems have been developed, such as hospital assistance and pedestrian tracking and many industrial applications.

\subsection{Integration of Curve Matching Framework and Heuristic Approaches}

The Kalman filter has been improved for an intelligent moving agent to obstacle avoidance in real time situations [23]. In this approach KF combined with a curve matching framework using a heuristic weighted mean of two methods to enhance prediction accuracy of target tracking and catch the image of obstacle in static or dynamic environment [32]. In an another work, the curve matched Kalman filter approach has been used for checking the repletion of characteristic motion patterns and how to track the obstacle and plan a path by its own intelligence [33]. The performance of the curve matching framework on real time obstacle avoidance system depends on efficient fusing of more number of sensor data. 


\subsection{Obstacle Avoidance with Kinect 3 D sensor Approach}

In this tracking and obstacle avoiding approach a control system of human motion with Kinect on-board a machine is proposed. Kinect 3D sensor is sufficient to detect the obstacle in its path in real time walking with the velocity be less than one meter per second [34]. This work is related to the development and implementation of autonomous sensor based moving machine [35]. A wireless camera has been used for capturing the image and Matlab has been used to process the image, which was followed by controlling the machine to detecting the obstacle in its path. This system allowed the machine to differentiate a obstacle in a picture. The Distance Transform for shaped based detection on a moving vehicle was also used [29]. This approach has its own limitations such as when camera gets nearer to an object which create problems in comparing to existing models of the object. To overcome this problem a high speed vision and sensing system has been used. The moving machine with Kinect was able to track a obstacle successfully and at the same time processes all the data in microcontroller, and activate the motor control system [7]. This method is more accurate because it can detect obstacle in its path and also avoid the obstacle in its path. To track the obstacle in real world situation the reference point of the system are longer than the centre of circle technology [36]. This technique will improve the ability of the Kinect sensor to operate indoor and outdoor environment.

\subsection{Wireless Communication}

The main aim of this embedded application is to design a PC controlled moving machine which can detect and avoid the obstacle in its path and all these functions have been completed wirelessly [37]. The Zig Bee is used for efficient wireless communication. The Trans - receive system has longitudinal and latitudinal value when the system detects the obstacle in its range [38]. The proposed system uses a infrared sensor in order to detect the moving obstacles in real time. The circuit was assembled on PCB for better processing. The aim of this work is to make a moving machine which will detect and avoid obstacle in its path and plan a safe using wireless communication technology [8]. This approach is very useful in the disaster locations and tries to find a safe path to move out of that location. Special passive infrared sensors are used for detection or tracking.

\subsection{Fuzzy logic Based Approach}

Fuzzy logic based systems have been developed earlier for hurdle avoidance in walking machine. The Fuzzy Logic Controller for intelligent moving machine takes input from two ultrasonic sensors mounted in front of the machine and path finding and planning is done [39]. First, the system will recognize the situation and then start completing the task which will observe the condition of obstacle is that static or moving type. Then this approach start doing work in appropriate manner and gives information to the controller to make a map to move safely in that environment. The controller is designed using Fuzzy Logic Toolbox of MATLAB and its implemented with the hardware system [40]. The programming of a moving machine is an important task for designing a real time obstacle avoidance system which is described by machine motion. The machine is manipulated and control by the program code which is based on fuzzy logic where the obstacle may or may not be in the path. The sensor plays a vital role in designing of the real time obstacle avoider machine. The main task is to interface with sensors and to get the desired response at the output [41].

\subsection{LabVIEW and FPGA Integrated Approach}

National instrument software architecture uses both lowlevel and high-level control. High-level tasks, such as obstacle avoidance and interpretation of sensor data, are executed on the embedded real-time processor; the obstacle avoidance algorithm uses the data from the IR and ultrasonic sensors to make decisions about how to capture its environment [42]. NI also has low-level control of the motors, which is implemented on the FPGA. Depending on the outcome of the obstacle avoidance algorithm, the data is transferred between the real-time processor and the FPGA using FPGA interface functions built into LabVIEW. With LabVIEW Real-Time, LabVIEW FPGA, and NI singleboard developers can rapidly design, develop, and deploy algorithms. The programming has been completed by LabVIEW because it is very popular and more sophisticated programming language.

\subsection{Classical Motion Planner}

Classical motion planners assume that the full knowledge of the geometry of the moving machine environment is known prior to move. In this the path is clear or also the type and location of obstacle known. A path is correct if it lies wholly within the free-space, and if the goal is reachable, connecting the initial position with the goal. Latombe [43], described a classical planner in some detail in his book, Machine Motion Planning, in which he splits the classical planner into three major categories: roadmap algorithms, cell decomposition methods and potential field approaches.

\subsection{Cell Decomposition Approach}

Although the concept of cell decomposition is quite simple, the implementation is more difficult. This group of algorithm split the space into parts; namely, obstacle space and free traversable space [44]. The exact variety of this group separates the space in trapezoids or polygons. The free space is constructed by combining all the separate free subspaces. In the approximate cell decomposition algorithms the space is discredited into small cell. If an obstacle is situated within a cell, the complete cell is disabled for traversal and thus the complete cell is added to the obstacle subspace. Just like the roadmap concept this group of algorithms constructs an obstacle free subspace wherein the moving machine is able to traverse without encountering an obstacle. Cell decomposition algorithms do not produce hard-to-follow one-dimensional curves but give safe corridors between obstacles. This property puts less pressure on tracking controllers but do not completely solve the path generation problem. As the moving machine depart from the starting point and the approaches to final destination which require the environment constraint such as moving in a crowded area where so many types of obstacles. The program must have control action and various approaches are used to reach to destination.

\subsection{Heuristic Planning Approach}

The class of heuristic planners, such as "Go To Waypoint" algorithm. This algorithm is based on the behaviour of moving machine [45]. The simplest version can be the following control program the machine bases its trajectory on pre-programmed situations and criteria and execute preprogrammed commands. Although heuristic planners are designed to work well in most environment configurations, 
they lack completeness. There is no guarantee that the algorithm will halt, or that the moving machine will be able to find the goal even if a path exists [46]. The location and the dimension of the objects in the path can be identified to a certain degree. The sensory information acts as a feedback for moving machines to work. The current position of the intelligent machines is usually done by the encoders that measures and compute the position of obstacle in the workspace. Sensing is used in motion to provide the feedback for force as control action.

\subsection{Embedded Based Approach}

The use of embedded approach for complex environment is based on design and optimization of control system. In embedded system transforms information collected from the sensors and optimized it. The algorithm allows the cost functions to use a local search function which adopts a step size of machine [28]. The control system is divided into multiple input and single output. The software implementation has been done by coding technique to control the system. This approach learns from the behaviour of the user. This technique is found successful for all static and dynamic type of obstacles. This approach can easily be implemented with tools and data available which may be conflicting [38].

\subsection{A Dynamical System (DS) Based Approach}

The obstacle avoidance in fast moving machine can adapt a target and obstacle position in dynamically motion environment [47]. Dynamical system are embedded into model considered the current position of the machine, the target, and all other working space. To model the moving machine with DS having situation where there is no time to plan, no matter how fast the planning to design and dynamically changes [40]. The Dynamic environments contain both the static and dynamic challenge for obstacle avoidance. In early days the learning system introduce by map and map motion where avoiding real-time models. The derivation of dynamic system is simple and systematic; the resulting equations of motion, control devices, and gear friction are nonlinear differential equations. The dynamic equations can be applied to the link sequentially and follow the instruction forward and backward. The Incremental Hierarchical Discriminate Regression was used to find the results of obstacle avoidance moving machine [48].

Table -1 Literature Review Of Moving Machine

\begin{tabular}{|l|l|l|l|}
\hline $\begin{array}{l}\text { S. } \\
\text { No }\end{array}$ & $\begin{array}{l}\text { RESEARCH } \\
\text { AREA }\end{array}$ & GOAL & REFERENCES \\
\hline 1. & $\begin{array}{l}\text { Neural Based } \\
\text { Approach }\end{array}$ & $\begin{array}{l}\text { For obstacle } \\
\text { detection and } \\
\text { assisting of } \\
\text { human }\end{array}$ & $\begin{array}{l}\text { Horn (1981) } \\
{[49], \text { Jones }} \\
(1999) \text { [46] and } \\
\text { Romdhani } \\
(2001)[35]\end{array}$ \\
\hline 2. & $\begin{array}{l}\text { Distributed } \\
\text { Sensor } \\
\text { Network } \\
\text { Approach }\end{array}$ & $\begin{array}{l}\text { This intelligent } \\
\text { machine } \\
\text { design for } \\
\text { avoiding } \\
\text { obstacle which } \\
\text { may be static } \\
\text { or dynamic. }\end{array}$ & $\begin{array}{l}\text { Haralick } \\
(1993)[9], \\
\text { Gavrilla } \\
(1999)[2], \\
\text { Graham } \\
(2003)[50], \\
\text { Lang (2003) and } \\
\text { Moreno } \\
(2003)[3]\end{array}$ \\
\hline
\end{tabular}

\begin{tabular}{|c|c|c|c|}
\hline 3. & $\begin{array}{l}\text { Vision Based } \\
\text { Approach }\end{array}$ & $\begin{array}{l}\text { This moving } \\
\text { machine } \\
\text { design for } \\
\text { industrial } \\
\text { purpose. }\end{array}$ & $\begin{array}{lr}\text { Adam } & (2000) \\
{[19],} & \text { Zhou } \\
(2001), & \text { Treptow } \\
(2005), & \text { Hyams } \\
(2005) & \text { and } \\
\text { Yoshimi } & (2006)\end{array}$ \\
\hline 4. & $\begin{array}{l}\text { Silhouette } \\
\text { Extraction } \\
\text { Approach }\end{array}$ & $\begin{array}{l}\text { The machine } \\
\text { design for } \\
\text { industrial and } \\
\text { as a human } \\
\text { assisting agent. }\end{array}$ & $\begin{array}{l}\text { Gavrilla } \\
(1999)[2], \\
\text { Lindstrom } \\
(2001)[25], \\
\text { Wang } \\
(2003)[51], \\
\text { Topp (2005)[41] }\end{array}$ \\
\hline 5. & $\begin{array}{l}\text { Peer-to-Peer } \\
\text { Communication } \\
\text { Approach }\end{array}$ & $\begin{array}{l}\text { Autonomous } \\
\text { indoor } \\
\text { machines is } \\
\text { very important } \\
\text { and design for } \\
\text { indoor } \\
\text { challenging } \\
\text { task. }\end{array}$ & $\begin{array}{l}\text { Coaniciu } \\
(2003)[26], \\
\text { Fritsch } \\
(2003)[14] \text { and } \\
\text { Marti } \\
(2008)[18]\end{array}$ \\
\hline 6. & $\begin{array}{lr}\text { Optical } & \text { Flow } \\
\text { and } & \text { Kalman } \\
\text { Filter } & \end{array}$ & $\begin{array}{l}\text { Motion } \\
\text { analysis } \\
\text { moving } \\
\text { machine. }\end{array}$ & $\begin{array}{l}\text { Borenstein } \\
\text { (1991)[52], } \\
\text { Motai } \\
(2005)[53] \text { and } \\
\text { Mataric Maja } \\
(2007)[48]\end{array}$ \\
\hline 7. & $\begin{array}{ll}\text { Integration of } \\
\text { Curve } \\
\text { Matching } \\
\text { Framework }\end{array}$ & $\begin{array}{l}\text { For real-time } \\
\text { obstacle } \\
\text { avoidance. }\end{array}$ & $\begin{array}{l}\text { Wolfson } \\
\text { (1990)[54] and } \\
\text { Rastogi } \\
(1997)[55]\end{array}$ \\
\hline 8. & $\begin{array}{ll}\text { Obstacle } & \\
\text { Avoidance with } \\
\text { Kinect } \quad 3-D \\
\text { sensor } \\
\text { Approach. }\end{array}$ & $\begin{array}{l}\text { For detecting } \\
\text { of human } \\
\text { motion and } \\
\text { control. }\end{array}$ & $\begin{array}{l}\text { Beymer } \\
(2002)[56], \\
\text { Ramanan } \\
(2003)[33], \\
\text { Marti (2008) } \\
\text { and Ilias } \\
(2014)[12]\end{array}$ \\
\hline 9. & $\begin{array}{l}\text { Wireless } \\
\text { Communication }\end{array}$ & $\begin{array}{l}\text { Finding } \\
\text { location and to } \\
\text { used for as a } \\
\text { path finder. }\end{array}$ & $\begin{array}{lr}\text { Sandeep } & \text { (2010), } \\
\text { Welch } & (2011) \\
\text { and } & \text { Awad } \\
(2014) & \end{array}$ \\
\hline 10. & $\begin{array}{l}\text { Fuzzy Logic } \\
\text { Based } \\
\text { Approach }\end{array}$ & $\begin{array}{l}\text { Hurdle } \\
\text { avoidance } \\
\text { walking } \\
\text { machine. }\end{array}$ & $\begin{array}{l}\text { Burridge (2001) } \\
\text { and Song (2014) }\end{array}$ \\
\hline 11. & $\begin{array}{l}\text { LabVIEW and } \\
\text { FPGA } \\
\text { Approach }\end{array}$ & $\begin{array}{l}\text { Industrial } \\
\text { Application. }\end{array}$ & NI Systems \\
\hline 12. & $\begin{array}{l}\text { Classical } \\
\text { Motion Planner }\end{array}$ & $\begin{array}{l}\text { Machine } \\
\text { intelligence } \\
\text { according to } \\
\text { the } \\
\text { environment. }\end{array}$ & $\begin{array}{l}\text { Latombe } \\
\text { (1991)[57] }\end{array}$ \\
\hline 13. & $\begin{array}{l}\text { Cell } \\
\text { Decomposition } \\
\text { Approach }\end{array}$ & $\begin{array}{l}\text { Moving } \\
\text { machine for } \\
\text { hospital and } \\
\text { airport used as } \\
\text { a payload } \\
\text { machine. }\end{array}$ & $\begin{array}{l}\text { Nelson (1997) } \\
\text { and Perez } \\
(2008)[58]\end{array}$ \\
\hline
\end{tabular}




\begin{tabular}{|c|l|l|l|}
\hline 14. & $\begin{array}{l}\text { Heuristic } \\
\text { Planning } \\
\text { Approach }\end{array}$ & $\begin{array}{l}\text { As a load } \\
\text { machine for } \\
\text { house } \\
\text { application. }\end{array}$ & $\begin{array}{l}\text { Koren (1991) } \\
\text { and Jefferies } \\
(2003)\end{array}$ \\
\hline 15. & $\begin{array}{l}\text { Embedded } \\
\text { Based } \\
\text { Approach }\end{array}$ & $\begin{array}{l}\text { Design for } \\
\text { complex } \\
\text { environment. }\end{array}$ & $\begin{array}{l}\text { Kim (2004) and } \\
\text { H.Hu (2006) }\end{array}$ \\
\hline 16. & $\begin{array}{l}\text { Dynamical } \\
\text { Based } \\
\text { Approach }\end{array}$ & $\begin{array}{l}\text { Obstacle } \\
\text { avoidance and } \\
\text { find a safe } \\
\text { path for } \\
\text { moving } \\
\text { machine. }\end{array}$ & $\begin{array}{l}\text { Tomasi (1992), } \\
\text { Pratiha (2002) } \\
\text { and Lee (2006) }\end{array}$ \\
\hline
\end{tabular}

The functional block diagram of IMM is shown in Fig.1.

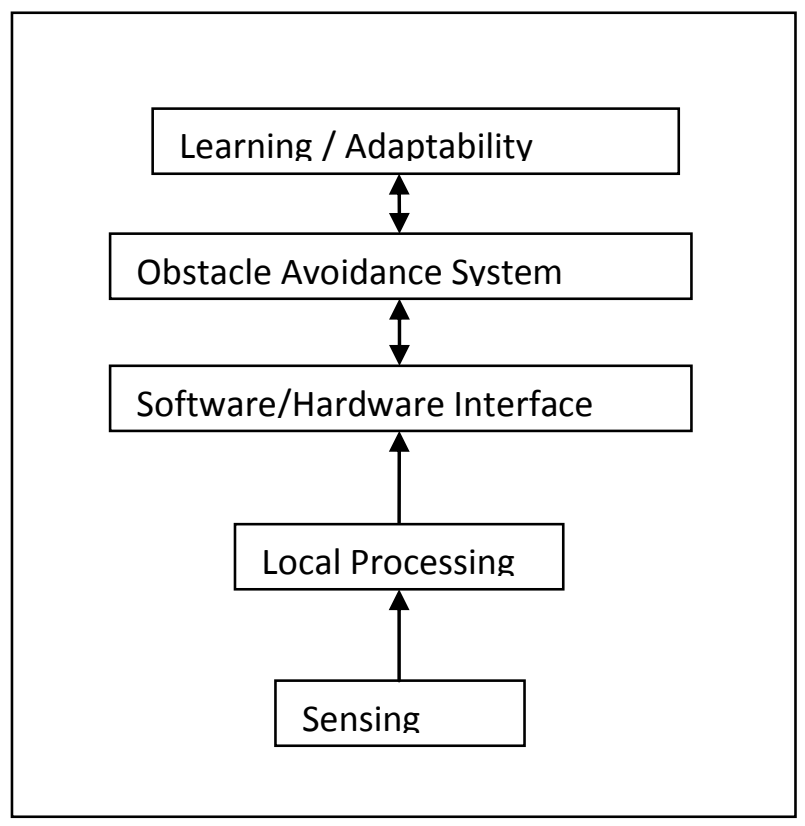

Fig. 1 Block diagram of IMM

\section{CONCLUSIONS}

The paper explains a chronological review of intelligent moving machines used in various sectors. The overview is mainly divided in two parts, first part deals with the applications of intelligent moving machine in different areas and second part explains the approaches used to make the machine intelligent.

\section{REFERENCES}

[1] Gavrila.D.M, "The visual analysis of intelligent machine movement: a survey. Digital Image Understand 73(1): pp.82-98, 1999.

[2] Gavrila.D.M and Philomin.V, "Real-time object detection for smart vehicles", in IEEE International Conference on Computer Vision, 1999.

[3] Moreno.J and Dapena.P , “ Path quality measure for sensor-based motion planning". Robotics and Autonomous systems, vol . 44, pp. 131-150, 2003.

[4] Spinello.L and Arras.A, "People Detection in RGB-D Data”, in Proc. of IROS, pp.3838-3843, 2011.

[5] Welch.G and Bisho.H , "An Introduction to the Kalman Filter”, UNC-chapel, TR 95-041, 2006.
[6] Satake.J and Miura.J, "Person Following of a Moving Machine using Stereo Vision", Journal of the Machine Society of Japan, vol.28, no.9, pp.1091-1099, 2010.

[7] Song.G, Wei.Z and Song.A, "A hybrid sensor network system for home monitoring applications", IEEE Trans Consumer Electronics, vol.53, no.4, pp.143414, 2007.

[8] Patel.H and wankhade.M, "Human tracking in video surveillance" International Journal of Emerging Technology and Advanced Engineering, ISSN 22502459, December 2011.

[9] Haralick .R.M and Shapiro.S.M, Computer and Machine Vision, Addison-Wesley, 1993.

[10] Jung.J and Sukhatne G.S , "Detecting moving objects using a single camera on a moving machine in an outdoor environment", In: Proc. Of International Conference on Intelligent Autonomous Systems, pp.980-987, 2004.

[11] Ryan.J, Zennaro.M, and Howell.A, "An overview of emerging results in cooperative MAV control", Proc. Of 43rd IEEE Conference on Decision and Control, vol. 1, pp.602-607, 2007.

[12] B. Ilias , R. Nagarajan , and M. Murugappan , "Hospital nurse following machine :hardware development and sensor integration. International Journal of Medical Engineering and Informatics (IJMEI) 6(1): 1-13, Inderscience, ISSN; 1755-0653 (print), 1755-0661 (online), 2014.

[13] Messelodi .S, Modena.C.M and Zanin.M , "A computer vision system for the detection and classification of vehicles at urban road intersections , Pattern Anal Appl 8 (1-2) : pp. 42-56, 2005

[14] Fritsch. J, Kleinehagenbrock. J, and Lang. S, "Multimodal anchoring for human-machine attraction", Robotics and Autonomous systems, vol.43, pp.133$147,2003$.

[15] Lee.J , Tsubouchi.T , Yamamoto.K , \& Egawa.S , "People tracking using a machine in motion with laser range finder , Proc. Of the 2006 IEEE / RSJ International Conference on Intelligent Machine and Systems (IROS2006) , pp. 2396-2942 , Beijing, China , Oct 2006.

[16] Pratiha. D.K, Deb. K, and Ghosh .A, "Optimal path and gait generationSimultaneously of a six-legged moving machine using a GA-fuzzy approval", Robotics and Autonomous systems Journal, vol.41, issue 1, pp.1-20, 2002.

[17] S.J. Kim, W.K. Choi, and H.T. Jeon, "Intelligent machine control with personal digital assistants using Fuzzy logic and Neural network, in: Knowledge-Based Intelligent Information and Engineering Systems, Pt 3, Proc. vol. 3215 , pp.589-595, 2004.

[18] Marti.M.J , Foster.F and Wahi.N, "Multi-sensor human tracking", Univ. of New South Wales course project report. 2008.

[19] Adam.A, Rivlin.E, and Shimshoni.I , "Computing the sensory uncertainty field of a Vision-based localization sensor ," proc . Of the IEEE International Conference on Robotics \& Automation, pp. 2993-2999, April 2000 . 
[20] Franz, M.O and Krapp , H.G., "Wide-field motionsensitive neurons and Matched filters for Optic flow fields". Biological Cybernetics, 83: 185-197, 2000.

[21] Lee.J.H , Appenzeller.G , and Hashimoto.H , “ An agent for intelligent spaces : Functions and roles of machine intelligent in sensored, networked, thinking spaces, IEEE conference Intelligent Transportation Systems, Boston, pp. 983-988, 1997.

[22] Lee.Z.H and Hashimoto.H, "Intelligent Machine control by distributed sensors," proc. Of IFAC Workshop Moving Machine Technology, pp. 85-90, 2001.

[23] Xu .F and Fujimara.K , "Human Detection using Depth and Gray images"Proc.of AVSS , pp.115-121, 2003.

[24] Tomasi, C. and Kanade, T., "Shape and motion from image streams under orthography". International Journal of Computer Vision, 9(2) :137-154, 1992

[25] Lindstrom.M and Eklundh.E , "Detecting and tracking moving objects from a mobile Platform using a laser range scanner", in Proc. IEEE / RSJ Int. conf. Intell Robots Syst ,Mani , HI , vol.3 , pp. 1364-1369 , 2001.

[26] Coaniciu. D, Ramesh. V and Meer. P, "Kernel-based object tracking"on Pattern Analysis and Machine Intelligent, vol.25 no.5, pp.564-577, May 2003.

[27] Gavrila D.M, "The visual analysis of human movement". Computer Vision and Understanding, 8298, 1999.

[28] Khati. O, "Real-time obstacle avoidance for manipulators and moving machine", International Journal of Moving Machine Research, vol.5 no.1, pp.90-98, 1986

[29] Moeslund, T.B. and Granum , E., "A survey of computer vision-based human motion capture". Computer Vision and Image Understanding, 81: 231$268,2001$.

[30] Barraquand. J and Latombe .J.C, "Machine motion planning: a distributed representation Approach", International Journal of Robotics Research, vol.10 no.6, pp. 628-649, 2006

[31] Nelson.C and Polona.P ," Detection and recognition of periodic, non-rigi motion. Int. J Comput vis 23,261 $282,1997$.

[32] Han. H.K , Kim .B.K , and Lee. M , "Active calibration of the machine / camera pose Using the circular objects," Trans. on Control , Automation and Systems Engineering (in Korean), vol.5 , no.3 , pp. 314-323, April , 1999.

[33] Ramanan.D and Forsyth.A, "Finding and tracking people from the bottomup", in Proceeding of Computer Vision and Pattern Recognition (CVPR), Madison Wisconnin , June 2003

[34] Beymer.D and Konolig.K, "Tracking obstacle from a moving platform. Int. Proceeding of 202 int. Symp. On Experimental Machines. pp. 234-244, 2002.

[35] Romdhani.S et al.: Computationally Efficient Face Detection, Proceedings of the 8th International Conference on Computer Vision, 2, p.2001.
[36] Jefferies. M. E, Baker. J, and Weng . W, "Machine IntelligentCognitive Mapping: A role for a global metric map in a cognitive process". In Workshop on Machine and Cognitive Approaches to Spatial Mapping, 2003

[37] Sandeep Bhatia, Ajay Mudgal, and Amita Soni, "Alive Human Detection Using an Autonomous Mobile Rescue Robot", Department of Electrical \& Electronics, PEC University of Technology, Chandigarh, India vol.no.2, July 2010.

[38] Awad. F and Shamroukh.R , "Human Detection by Intelligent Machine Urban Search and Rescue Using Image Processing and Neural Networks" International Journal of Intelligent Science , pp.4 39-53, 2014.

[39] Burridge.R and Graham, "Providing machine assistance during extra-vehicular activity", SPIE, 2001.

[40] Perrone J.A. and Thiele.A, "A model of speed taning in M T neurons". Vision Research, 42(8): 1035-1051, 2002. Patnaik.S, Jain.S, and Tzafesta.Ss, "Innovations in intelligent machine and control", Springer, 2006.

[41] Topp.E.A and Christensen.H.I, "Tracking for following and passing persons", in Proc. IEEE / RSJ Int. conf. Intell. Machine Intelligent Syst., Edmonton, A.B, Canada, pp.710-715, 2005.

[42] Borenstein.J and Koren.K, "Obstacle Avoidance with Ultrasonic Sensors". IEEE Journal of Robotics and Automation, vol. RA-4, No.2, pp. 213-218, 1988.

[43] Luo.R.C , Chen.Y, and Liao.C.T,"Mobile robot based human detection and tracking using range and intensity data fusion", in Proc. IEEE Workshop Adv. Robot. Social Impacts, pp. 1-6, 2007.

[44] Okusako.O , and Sakane.S , "Human tracking with a Intelligent machine using a laser range- Finder Journal of Robotics Society of Japan, vol.24 no.5, pp. 605-613, July 2006.

[45] Borenstein .J, and Koren. K, "The vector field histogram-fast obstacle avoidance for mobile robots, IEEE Trans. on Robotics and Automation, pp.501-518, 1991.

[46] Jones. M .: Statistical Color Models with Application to skin Detection, IEEE Conference on Computer Vision and Pattern Recognition, 1, p. 274-280, 1999.

[47] Urzelai.J and Ezkerra.M, "Fuzzy controller for wallfollowing with a non-holonomous mobile robot" FUZZY-IEEE / IFES, BARCELONA, July, 1997.

[48] Mataric .Maja.J, "The Robotics Primer, MIT Press, Cambridge P.300, 2007.

[49] Horn. B and Schunck. B, "Determining Optical Flow" Artificial Intelligence, 17: 185- 203, 1981

[50] Graham .J and Shillcutt. K, "Robot tracking of human subjects in field environment", Proceedings of the International Symposium on Artificial Intelligence, Robotics, and Automation in space, 2003.

[51] Wang.L , Tang.T , Ning .H and Hu.W , "Silhouette analysis-based gait recognition for human identification. IEEE Trans Pattern Anal Mach Intell 25(12) : pp.1505-1518, 2003 
[52] Borenstein. J and Koren. K, "Real- time obstacle avoidance for fast moving machine", IEEE Transactions on system, Man and Cybernetics B , vol.19 no.5 pp. 1179-1187, 1989.

[53] Motai.Y, Visual-based human-machine interaction for extracting salient features of An industrial object for an automated assembly system, special issue on Machine Vision, International Journal of Computers in Industry 56 (8-9) pp.943-957, 2005.

[54] Wolfson.J.H, “On curve matching IEEE Trans. Pattern Anal Mach Intell 12, pp.483-489, 1990.
[55] Rastogi.A.K , Chatterji.B.N , Ray A.K . "Design of a real-time tracking system for fast-moving objects IETE J. Res 43, pp.359-369, 1997.

[56]Beymer.DandKonolige.K,Trackingobjectfromamobilep latform. In IJCAI-2001 Workshop on Reasoning with Uncertainty in Machine, Seattle, USA, 2001.

[57] Latombe .J.C, Machine Motion Planning , Kluwer Academic Publishers, Boston, MA ; 1991.

[58] Perez.L.G, Alegre.M , Ribeiro.A , " Perception and tracking of dynamic objects For optimization of avoidance strategies in autonomous piloting of vehicles", Paper Presented at International Conference Spatial Cognition , pp.500-519, 2004. 